\title{
Psicoterapia e Luto: A Vivência de Mães Enlutadas
}

\author{
Luís Henrique Fuck Michel ${ }^{1}$ \\ ${ }^{1}$ Universidade Federal do Paraná, PR, Brasil.
}

\author{
Joanneliese de Lucas Freitas ${ }^{1}$ \\ ${ }^{1}$ Universidade Federal do Paraná, PR, Brasil.
}

Resumo: Pesquisas empíricas sobre psicoterapia ainda são escassas no Brasil. Uma das maneiras de melhor avaliar os processos psicoterapêuticos é por meio do relato dos pacientes. O processo psicoterápico de enlutados é pouco estudado, a despeito de sua demanda por psicoterapia. Não há, na literatura nacional, pesquisas que abordem especificamente a experiência de psicoterapia de mães enlutadas. O presente estudo se propõe a compreender como as mães vivenciam esse processo. Este é um estudo qualitativo, em que se utilizou o método fenomenológico. Foram entrevistadas quatro mães. As entrevistas tiveram início com a pergunta disparadora: "Você pode relatar a vivência de seu processo terapêutico durante oluto?". Depois de transcritos, os relatos foram analisados a partir dos quatro passos metodológicos desenvolvidos por Giorgi. A análise das entrevistas revelou 18 elementos constituintes, que foram divididos em três eixos temáticos, a saber: relação terapeuta-paciente, possibilidades expressivas que emergem da relação psicoterápica e ressignificação. Concluiu-se que essa é uma vivência de uma relação particular estabelecida entre a mãe enlutada e o psicoterapeuta, da qual podem emergir possibilidades de ressignificação da sua relação com seus filhos falecidos, com seus familiares, com a morte e com a própria vida, desde que se sintam acolhidas, compreendidas e adquiram confiança para se expressarem livremente. Os dados nos levam a questionar se um projeto psicoterápico, livre de limites quanto aos temas abordados e em relação a objetivos prévios, poderia ser benéfico para pessoas enlutadas.

Palavras-chave: Luto, Luto materno, Psicoterapia, Psicologia fenomenológica.

\section{Psychotherapy and Bereavement: The Experience of Mourning Mothers}

\begin{abstract}
Empirical researches on psychotherapy are still very few in Brazil. Psychotherapeutic processes of bereaved are even less studied, despite their demand for psychotherapy. There is no research in Brazil approaching the psychotherapy experience of bereaved mothers. One way to best assess the psychotherapeutic processes is by analyzing the patients' reports. The present study intends to understand how mothers live this process. From the phenomenological method, this qualitative study conducted interviews with four mothers who participated in a bereavement support group, triggered by the question: "Could you please tell us about your psychotherapeutic process during bereavement?" Once transcribed, the reports were analyzed following Giorgi's methodological steps. The interviews' analysis revealed 18 constituents, divided into three thematic axes: patient-therapist relationship, expressive possibilities emerging from the psychotherapeutic relationship, and resignification. The study concluded that this is an experience of a specific relationship established between the mourning mother and her psychotherapist, from which resignifying possibilities may emerge, about mother's relation with her deceased child, with her relatives, with death, and even with life, as long as she is accepted, understood and acquire the confidence to express herself freely. These findings raise questions on whether a psychotherapeutic project, unlimited concerning dealt topics, and pre-established goals would not benefit people dealing with mourning.
\end{abstract}

Keywords: Bereavement, Maternal grief, Psychotherapy, Phenomenological psychology. 


\title{
Psicoterapia y Duelo: la Vivencia de Madres Enlutadas
}

\begin{abstract}
Resumen: Las investigaciones empíricas sobre psicoterapia todavía son escasas en Brasil. Una de las maneras de evaluar mejor los procesos psicoterapéuticos es el relato de los pacientes. El proceso psicoterápico de enlutados es poco estudiado a pesar de su demanda por psicoterapia. No hay en la literatura nacional investigaciones que traten específicamente de la experiencia de psicoterapia de madres enlutadas. El presente estudio se propone comprender cómo estas madres vivencian ese proceso. Este es un estudio cualitativo que utilizó el método fenomenológico. Se entrevistaron a cuatro madres. Las entrevistas comenzaron con la pregunta disparadora:“¿Puedesrelatarnosla vivencia de tu proceso terapéutico durante el duelo?”. Después de transcribir los relatos, los datos se analizaron a partir de los cuatro pasos metodológicos desarrollados por Giorgi. El análisis de las entrevistas reveló 18 elementos constituyentes, que se dividieron en tres ejes temáticos: relación terapeuta-paciente, posibilidades expresivas que emergen de la relación psicoterápica, y resignificación. Se concluyó que esta es una vivencia de una relación particular establecida entre la madre enlutada y el psicoterapeuta, de la cual pueden surgir nuevas significaciones de la relación con sus hijos fallecidos, con sus familiares, con la muerte y con la propia vida, desde que se sientan acogidas, comprendidas y adquieran confianza para poder expresarse libremente. Estos datos nos llevan a cuestionar si un proyecto psicoterápico, libre de límites a los temas abordados y en relación a objetivos previos, podría ser más beneficioso para personas enlutadas.
\end{abstract}

Palabras clave: Duelo, Duelo materno, Psicoterapia, Psicología fenomenológica.

\section{Introdução}

Pesquisas sobre psicoterapia começaram a surgir na primeira metade do século XX. As publicações nacionais sobre o tema são, em sua maioria, limitadas a revisões de literatura e textos teóricos, estando ainda muito aquém dos estudos empíricos produzidos no exterior (Pieta, Castro, \& Gomes, 2012). No que diz respeito aos modos de avaliar o processo psicoterápico, Pieta et al. (2012) apontam que uma das melhores maneiras de o fazer seria por meio do relato dos pacientes sobre suas experiências. Afinal, a partir de seus relatos, diversos elementos e informações relevantes relacionadas aos efeitos da psicoterapia podem ser revelados e então acessados tanto pelo pesquisador quanto pelos profissionais em geral. Stiles (2012) vai ao encontro dessa ideia ao afirmar que se deve enfatizar o modo como as pessoas mudam durante $o$ processo e como a psicoterapia facilita essas mudanças. Ekroll e Rønnestad (2017) também atentam para a importância de explorar a experiência subjetiva dos pacientes, principalmente no que diz respeito aos processos e mudanças. Em seu estudo, apontam que as experiências de mudanças cognitivas e de atitude são as mais descritas pelos pacientes em terapias tidas como de bons resultados.

Nas últimas décadas, uma quantidade considerável de estudos empíricos tem apontado para o impacto da relação terapêutica no processo (Gelso, 2014). Entende-se que os eventos significativos de mudança ocorrem a partir de um relacionamento genuíno e de confiança estabelecido com o terapeuta (Sousa e Vaz, 2017). Além disso, em um ambiente no qual os pacientes têm a possibilidade de se sentir seguros e apoiados, experiências pessoais relevantes podem ser desveladas. Os resultados apontam também que a percepção da existência de novas possibilidades de viver é um dos ganhos atribuídos pelos pacientes à psicoterapia. De acordo com Sousa e Vaz (2017), esse processo é marcado por um período de desestabilização da visão de mundo dos pacientes, mas que, por ser vivenciado em um contexto seguro, proporciona o surgimento de novas possibilidades.

Um dos raros estudos empíricos realizados no Brasil sobre a experiência de estar em psicoterapia partiu do pressuposto de que "a qualidade de uma experiência terapêutica é criticamente percebida pelo sujeito (paciente, cliente, etc.) e avaliativamente expressa em 
seu discurso" (Gomes, Reck, \& Ganzo, 1988, p. 190). Nesse estudo, a experiência de sentir-se livre ao falar e o alcance de uma compreensão mais acurada dos próprios problemas foram entendidos como experiências que indicaram progressos. Para alguns entrevistados, o autoconhecimento foi percebido como o único benefício da psicoterapia. Outros notaram mudanças no modo de ver as coisas e reestruturá-las, e alguns outros em relação à experiência interpessoal. Após um intervalo de dois anos da realização desse estudo, os entrevistados foram procurados para uma entrevista de seguimento (Gomes, 1990), que concluiu que as descrições dos participantes forneceram um retrato realista $\mathrm{e}$ abrangente do processo.

Uma meta-análise com estudos qualitativos e orientados para a descoberta sobre o mesmo tema contemplou nove categorias descritivas sobre como os pacientes compreendem a experiência de estar em psicoterapia (Timulak, 2007). Dentre essas categorias, encontram-se relatos sobre tomada de consciência e autocompreensão, mudanças de comportamento, reconhecimento da própria capacidade, alívio (por sentir-se em um ambiente seguro, sem ser julgado), possibilidade de experienciar e explorar emoções, sentir-se entendido, reconhecimento de si como uma pessoa ativa no processo terapêutico, sensação de segurança e da existência de suporte, além da experiência de proximidade e abertura do terapeuta. $\mathrm{O}$ autor também concluiu que a experiência de se sentir compreendido em psicoterapia possibilita a emersão de uma experiência interpessoal única. Em um estudo posterior, Timulak (2010) ressaltou o fato de que pacientes parecem valorizar mais os aspectos relacionais do processo do que os próprios terapeutas. Esse dado se torna ainda mais relevante se considerarmos as conclusões de Lambert (2013), que demonstra que mudanças negativas durante a terapia geralmente estão associadas à natureza da relação terapêutica.

\section{Luto e psicoterapia}

No que diz respeito a pacientes enlutados, um estudo de caso sobre a experiência em psicoterapia de uma viúva, conduzido por Ferreira, Leão e Andrade (2008), revela que com o processo a participante se sentiu fortalecida para enfrentar as dificuldades que surgiram depois da viuvez. De acordo com ela, a terapeuta foi uma mão amiga em um momento em que procurou poupar os familiares, omitindo deles seu sofrimento. Ela apontou também que sua psicoterapia foi funda- mental para que conseguisse "retomar a vida". Dentre os diferentes tipos de perda, aqui nos interessa o luto pela morte de um filho. Essa perda nos parece merecer atenção particular por ser frequentemente referida na literatura como um evento destruidor, capaz de estremecer os "pilares da vida" (Lopes \& Pinheiro, 2013; Oishi, 2014), e que é tido por muitas mães enlutadas como "a pior dor do mundo" (Freitas \& Michel, 2014).

Embora estudos clássicos sobre o luto o descrevam como uma reação diante de uma perda (Franco, 2010; Parkes, 1998), há diferentes perspectivas sobre os modos de descrever essa experiência e, consequentemente, sobre seus modos de cuidado (Freitas, 2018). No presente trabalho, optou-se pela perspectiva fenomenológica que propõe um retorno às experiências do humano no mundo, ou àquilo que nomeia como mundo-da-vida. Estudos em psicologia fenomenológica que buscaram descrever essa experiência radical e singular do luto materno apontam que a perda de sentido do mundo-da-vida é intrínseca e central na vivência desse luto (Brice, 1991; Freitas \& Michel, 2014; Martins, 2001; Silva, 2013), assim como a dor, que em alguns casos chega a adquirir uma expressão física (Freitas \& Michel, 2015; Gudmundsdottir, 2009). O luto materno é ainda fortemente marcado pela experiência de culpa (Alarcão, Carvalho, \& Pelloso, 2008; Barr \& Cacciatore, 2008; Gerrish, Neimeyer, \& Bailey, 2014). Além disso, sobre esse contexto, faz-se mister destacar que vivemos um momento histórico em que a expressão pública do sofrimento de enlutados se tornou interdita, devendo ser expressa com discrição (Ariès, 1975/2003; Koury, 2010). Não suportando enfrentar os sinais da morte, a sociedade procura suprimir os sinais do luto (Kovács, 1992). Concomitantemente, os próprios enlutados percebem os demais como incapazes de compreendê-los, preferindo não falar sobre seu sofrimento com os outros (Koury, 2010).

Ao acompanhar as reuniões de um grupo de apoio mútuo para enlutados, os autores do presente estudo notaram que a maior parte de seus membros assíduos era composta por mães. Durante as reuniões, elas relatavam, de modo recorrente, experiências extremamente negativas que tiveram com profissionais de saúde quando da morte de seus filhos, dentre os quais se incluem os psicoterapeutas. Por outro lado, eram também relatadas experiências consideradas positivas, percebidas por elas como fundamentais para que retomassem suas vidas. As situações antagônicas tinham em comum a ausência de clareza na descrição do que fora vivenciado. A partir desse con- 
texto vivencial e do apontado pela literatura sobre a relevância da compreensão dos pacientes sobre seus processos psicoterápicos, temos por objetivo investigar como mães que perderam seus filhos vivenciaram seus processos de terapia no período de enlutamento.

\section{Método}

Orientados pelo objetivo de compreender a vivência de psicoterapia de mães enlutadas, optamos por realizar uma pesquisa qualitativa, utilizando o método fenomenológico. Essa escolha se justifica pelo fato de esse método possibilitar que o pesquisador apreenda o sentido ou significado que uma determinada vivência possui para a pessoa que a experienciou (Forghieri, 1993/2012). Foi utilizada a entrevista fenomenológica como recurso de investigação. A pesquisa foi aprovada pelo Comitê de Ética em Pesquisa do Setor de Ciências da Saúde da Universidade Federal do Paraná (UFPR), sob protocolo CAEE 47559415.8.0000.0102, e obedece às Diretrizes e Normas Regulamentadoras de Pesquisa Envolvendo Seres Humanos, estabelecidas pela resolução 466/12 do Conselho Nacional de Saúde.

\section{Participantes}

Em razão do sigilo, os nomes das participantes foram substituídos por nomes fictícios - Rachel, Cora, Cecília e Alice - inspirados em mulheres que ocupam lugar de destaque na literatura nacional.

Rachel perdeu sua filha mais nova, de 16 anos, em um acidente de carro. Ela procurou por psicoterapia em 2015, por indicação do grupo de ajuda mútua. O processo durou apenas seis sessões. Rachel afirmou que apesar dos atendimentos terem lhe ajudado, precisou interrompê-los por não ter tido mais tempo disponível, devido a compromissos familiares. Ela também relatou ter feito terapia anteriormente, três ou quatro meses após a morte da filha, ocasião em que compareceu apenas aos três primeiros atendimentos. A entrevista foi realizada seis anos e dez meses após a perda e quatro meses após o término do processo psicoterápico.

Alice perdeu seu filho quando ele tinha 12 anos, devido a uma cardiopatia congênita. Ela iniciou seu processo terapêutico dois meses após a morte do filho, sendo atendida por um ano e seis meses ao todo. O encerramento do processo foi sugerido pela psicoterapeuta. Alice resistiu inicialmente à sugestão, mas concordou em reduzir gradualmente a frequência das sessões até que se considerasse preparada para seguir sem terapia. A entrevista foi realizada dez anos depois da morte de seu filho, oito anos e cinco meses depois do encerramento da psicoterapia.

Cecília perdeu seu filho de 38 anos em decorrência de um câncer. Ela cuidou dele ao longo de todo o processo de adoecimento, desde o diagnóstico. Sua psicoterapia teve início no mesmo ano do falecimento por indicação do grupo de ajuda mútua. Ela ainda estava em atendimento quando a entrevista foi realizada, dez meses depois da perda.

Cora perdeu sua filha de 31 anos em decorrência de um câncer. Iniciou a psicoterapia cerca de um ano após a morte da filha, por indicação do grupo de ajuda mútua, e permaneceu em atendimento por um ano. A entrevista foi realizada dois anos e oito meses após o falecimento de sua filha, quatro meses após o encerramento do processo psicoterapêutico.

\section{Procedimentos e análise das entrevistas}

Todas as participantes da pesquisa frequentam um grupo de ajuda mútua na dor do luto, que é acompanhado pelos pesquisadores há seis anos. Esse é um grupo criado e coordenado por membros da comunidade, com reuniões semanais. O convite para participação na pesquisa foi realizado durante uma reunião do grupo. Foram utilizados os seguintes critérios de inclusão: ter perdido um filho ou filha e ter iniciado psicoterapia devido a essa perda. O único critério de exclusão foi ser menor de 18 anos. Após ter sido explicado o objetivo da pesquisa e enfatizado o compromisso do sigilo, quatro mães se dispuseram a conceder entrevistas. As entrevistas foram realizadas em local resguardado de interferência externa, no mesmo prédio onde acontecem os encontros do grupo. Antes do início de cada entrevista, o Termo de Consentimento Livre e Esclarecido (TCLE) foi lido e assinado pelas participantes. Com o consentimento, as entrevistas foram gravadas em áudio e transcritas posteriormente. Foram realizadas entrevistas abertas, sem restrição em relação à duração, todas pelo mesmo pesquisador. Em consonância com o método fenomenológico, foi utilizada a pergunta disparadora: "Você pode relatar a vivência de seu processo terapêutico durante o luto?”. As perguntas posteriores realizadas pelo entrevistador tiveram tanto o intuito de clarificar as descrições das participantes quanto o objetivo de produzir uma fala que se aproximasse mais fortemente de suas vivências, mantendo o caráter essencialmente fenomenológico da entrevista. 
As entrevistas foram analisadas por meio do método empírico-fenomenológico de investigação em psicologia desenvolvido por Amedeo Giorgi (Giorgi \& Sousa, 2010) que consiste em quatro passos que levam à estrutura da experiência que se pretende compreender, a saber: a) estabelecer o sentido geral; b) determinação das partes: divisão das unidades de significado; c) transformação das unidades de significado em expressões de caráter psicológico; e d) determinação da estrutura geral de significados psicológicos, por meio de suas constituintes essenciais (Giorgi \& Sousa, 2010).

\section{Resultados e discussão}

A análise das entrevistas revelou 18 elementos constituintes essenciais da vivência de psicoterapia de mães que perderam seus filhos, divididos em três eixos temáticos para uma melhor compreensão do todo da experiência. O eixo 1 - relação terapeuta-paciente - engloba as constituintes: sentir dificuldade inicial para falar, sentir-se acolhida, sentir-se escutada, sentir-se respeitada, sentir-se compreendida e raiva do psicoterapeuta. O eixo 2 - possibilidades expressivas que emergem da relação psicoterápica - compreende as experiências de: expressar-se livremente, sentir-se livre para abordar outros temas que não o luto, revelar o sentimento de culpa e poder se queixar dos familiares. O eixo 3 - ressignificação - é composto por: perceber novas possibilidades, alcançar autocompreensão, aceitar a morte, deixar de culpar os outros pela morte do filho, aceitar o modo dos outros de lidar com o luto, experiência de fortalecimento, sentir-se melhor de saúde e retomar a vida.

\section{Eixo 1: Relação terapeuta-paciente}

O primeiro eixo temático abrange experiências que dizem respeito à relação terapeuta-paciente e vai ao encontro de vários achados na literatura sobre a relevância da relação terapêutica na avaliação positiva do paciente sobre seu processo (Gomes et al., 1988; Souza e Vaz, 2017; Timulak, 2007, 2010). Os participantes do estudo de Souza e Vaz (2017) relataram que eventos significativos ocorreram em função de um relacionamento genuíno e de confiança com o terapeuta, no qual experimentavam um ambiente de segurança e apoio. Do mesmo modo, no presente estudo, além do fato de terem experienciado em psicoterapia a sensação de serem acolhidas e escutadas de modo respeitoso e compreensivo, são também apontadas pelas participantes as questões do sigilo e da ausência de julgamento moral por parte das terapeutas. Como descrito a seguir, elas afirmaram que se sentiram acolhidas, escutadas, respeitadas e compreendidas pelos seus psicólogos, embora por vezes tenham sentido dificuldade inicial para falar. Apesar de geralmente a relação ter aparecido com uma significação positiva, uma das participantes relatou ter sentido raiva do psicoterapeuta.

\section{Sentir dificuldade inicial para falar}

As entrevistadas relataram ter sido difícil falar sobre si mesmas em um período em que estavam sensíveis em razão da perda de seus filhos. Afirmaram que nas primeiras sessões choravam com frequência, sem conseguir falar. Essa situação foi mudando gradualmente e os choros se tornaram cada vez menos frequentes: "A primeira vez que eu vim falar com a [psicóloga] eu não conseguia falar, só chorava. A segunda também, mas aí já foi melhorando" (Cora). A dificuldade para falar foi também encontrada por Gomes et al. (1988). Eles afirmam que o bloqueio da fala é um modo pelo qual se apresenta a dificuldade dos pacientes para adentrar na dinâmica do processo. Segundo os autores, à medida que o paciente consegue ficar mais à vontade durante as sessões, as questões passam a ser apresentadas com menos angústia e com maior clareza.

\section{Sentir-se acolhida}

A experiência de sentir-se acolhida foi descrita por Cecília como a sensação de ser "abraçada" pela terapeuta. No entanto, ela destaca que esse acolhimento se situa em um modo particular de relação que se estabelece entre terapeuta e paciente, o que também foi ressaltado por Alice: "Ela me acolheu dentro da característica profissional dela . . . ela me ouviu... . ela viu que eu tava precisando muito ....". As entrevistadas associaram a experiência de terem sido acolhidas pelas psicólogas com uma postura de abertura afetiva e de disponibilidade para entendê-las: "É uma pessoa que tá com o coração aberto diretamente pra gente, né? Pra entender. . . e tem também toda parte de estudo, né? Que ela pode colaborar de que forma vai poder estar me abraçando, né?" (Cecília).

No estudo de Sousa e Vaz (2017), o sentir-se acolhido e seguro na relação terapêutica também foi apontado como relevante para os participantes. Segundo os autores, as dimensões essenciais da experiência de 
psicoterapia dependem da relação terapeuta-paciente. Essa conexão não se daria tanto de modo cronológico, mas de uma maneira interdinâmica e imprevisível. O acolhimento que aparece nos relatos das entrevistadas como percepção de disposição e abertura afetiva por parte do psicoterapeuta para compreendê-las foi apontado como uma condição para que se sentissem à vontade para se expressar: "Com a psicóloga, você se sente acolhido, né? Muita coisa que às vezes você não pode dizer no grupo, ou às vezes não se sente à vontade, ou às vezes ... é ... até por emoção, né?' (Cecília). Como é possível perceber no relato de Cecília, existem contextos em que as mães enlutadas não se sentem suficientemente acolhidas para se expor, diferentemente do que ocorre em psicoterapia.

\section{Sentir-se escutada}

As entrevistadas relataram que se sentiram escutadas por suas psicólogas quanto a seus sofrimentos e sentimentos que as demais pessoas não queriam escutar. A escuta que ocorre na psicoterapia ganha relevância ainda maior quando se nota sua ausência em outras relações. $O$ fato de ser escutada é de tamanha importância para Cora que chega a ser apontado por ela como a razão para que considere o psicólogo como um amigo: "Psicólogo pra mim, cês são amigos, que cês me escutam o que eu quero falar, né? E ali morre o assunto". No contexto em que as possibilidades de escuta são escassas, conversar com um profissional da área da saúde em quem se pode confiar, por ancorar sua prática no sigilo, pode ser benéfico para pessoas que vivenciam esse luto.

\section{Sentir-se respeitada}

A experiência de sentir-se respeitada foi apontada por Alice, especialmente ao falar sobre suas crenças e sua busca por conectar-se com o filho falecido por meio da espiritualidade. A atitude da terapeuta de não se posicionar quanto ao tema da espiritualidade, mas dar abertura para que Alice pudesse abordá-lo do modo que lhe fazia sentido, foi percebida pela entrevistada. $\mathrm{O}$ respeito às crenças das mães enlutadas em psicoterapia, oferecendo espaço para a questão, é parte relevante do trabalho com esse público, haja vista que a fé pode fornecer amparo e suporte para lidar com a dor desse luto, podendo também ser meio para que encontrem sentido ou explicação para a perda (Alarcão et al., 2008).

\section{Sentir-se compreendida}

As entrevistadas relataram que se sentiram compreendidas por suas psicoterapeutas. Tais relatos aparecem estreitamente vinculados à percepção de que se é escutada e respeitada. As mães afirmaram que ao se sentirem compreendidas, se sentiam à vontade para chorar, não importando o tempo que fazia desde que seus filhos haviam morrido, pois sabiam que as psicólogas entenderiam sua dor. A dor do luto materno é um sentimento de longa duração e pode acompanhar as mães por toda a vida, conforme aponta a literatura (Freitas \& Michel, 2014, 2015; Silva \& Melo, 2013). A compreensão desse sentimento, que uma das entrevistadas afirmou ter encontrado tanto no grupo de ajuda mútua quanto na psicoterapia, não faz parte do cotidiano dessas mães. Exatamente por isso, sentir-se compreendida é significativo para elas, pois é percebido como a permissão que precisam para se expressar, sem medo de julgamentos e sem a exigência de não chorar, como costuma ocorrer em outros contextos. Timulak (2007) aponta a experiência de se sentir compreendido em psicoterapia como aquela que possibilita a emersão de uma experiência interpessoal única.

Essa experiência também foi apontada por Cecília, que relatou ter percebido que sua terapeuta compreendia a impossibilidade de que ela voltasse a ser quem era antes da perda do filho. Ela afirmou que sofria com a cobrança de seus filhos para que voltasse a ser "a pessoa que era antes". A postura da terapeuta, porém, foi diametralmente oposta, possibilitando que ela se sentisse compreendida naquela relação.

\section{Raiva do psicoterapeuta}

A experiência de raiva do psicoterapeuta foi relatada por Rachel. A entrevistada procurou terapia cerca de três meses após a morte da filha. Durante a terceira sessão sentiu raiva do terapeuta quando ele lhe recomendou que ela vivesse pelos seus outros filhos:

\section{Me indicaram um psicólogo, eu fui, ele não conse- guiu . . . ele me fez exatamente essa pergunta, eu me lembro como se fosse agora: "Você ainda tem mais filhos?". Eu falei: "Eu tenho dois". "Então viva por eles e pelo seu marido". Nossa, eu queria matar ele! Eu queria arrebentar a cara dele!}

Rachel relatou que ao receber esse "conselho" do psicólogo interrompeu a terapia. Ela afirmou que se sentiu ferida e percebeu, por meio dessa fala, que 
ele não a compreendia e que não poderia "tratá-la" (sic). A opção por interromper o processo acontece, de acordo com o relato, quando ela nota que o terapeuta não compreende sua vivência, condição que acredita ser necessária para que a psicoterapia possa ocorrer.

$\mathrm{O}$ relato de Rachel indica que a experiência de estar em psicoterapia após a perda de um filho nem sempre é percebida como positiva ou benéfica pela mãe enlutada. Lambert (2013) aborda em seu estudo experiências negativas vividas em processos psicoterápicos em geral. De acordo com o autor, a psicoterapia pode resultar em mudanças negativas para o paciente, o que está geralmente associado à natureza da relação terapêutica. No caso de Rachel, a indisponibilidade do terapeuta para escutar e compreender seu luto e a proposta de uma alternativa simplista para que ela pudesse superá-lo estava mais centrada na resolução do que ele entendia como um problema do que de fato na significação do problema para Rachel.

\section{Eixo 2: Possibilidades expressivas que emergem da relação psicoterápica}

O segundo eixo temático apresenta as possibilidades expressivas que emergiram ancoradas nos sentimentos sedimentados por uma relação de confiança entre paciente e terapeuta. Como Sousa e Vaz (2017) asseveram, a construção de uma relação terapêutica confiável é primordial para o desdobramento da psicoterapia. A partir da relação assim estabelecida, as participantes puderam se expressar livremente sobre questões íntimas, relacionadas ou não com o luto, sentimentos socialmente percebidos como negativos, ou mesmo se queixar dos familiares. Além disso, essa relação se mostrou um ambiente privilegiado, uma vez que permitiu expressões que não eram possíveis em outras relações, tais como poder falar sobre seus filhos mortos ou expressar o sofrimento por sua perda sem a necessidade de demonstrar ou fingir certa "melhora".

\section{Expressar-se livremente}

Se a partir do século XX a comoção dos enlutados tornou-se motivo de embaraço, devendo ser escondida e evitada (Ariès, 1975/2003), as entrevistadas relataram que a psicoterapia lhes deu a possibilidade de falar sobre seus filhos, sobre a dor que sentem e sobre o modo como lidam com essa dor: "Aí eu precisei da terapeuta, porque lá era o momento de eu falar do [filho que faleceu] . . . pra eu dizer pra ela da dor que me cortava ... e o que eu fazia com aquela dor..." (Alice).
Koury (2010) afirma que, na sociedade brasileira contemporânea, os enlutados deixaram de expressar seu sofrimento por julgarem que os outros não são capazes de compreendê-los, compreensão que as entrevistadas afirmaram ter encontrado na relação com suas psicoterapeutas. Outra razão comum para que enlutados não exponham seu sofrimento é o desejo de poupar seus familiares, para que eles não sofram mais ao perceberem sua dor (Ferreira et al., 2008). A necessidade de ocultar o sofrimento não parece existir na psicoterapia, como pôde ser observado no relato das mães entrevistadas. Elas afirmaram que durante as sessões podiam chorar, expressar seus posicionamentos e suas dificuldades, como o desânimo, a fraqueza, o desconforto, a saudade e a tristeza que sentiam.

No caso de Cecília, que recebia em casa a cobrança dos filhos para que melhorasse logo (ou ainda, para que deixasse de sofrer), essa possibilidade mostrou-se extremamente significativa. Cora, por sua vez, afirmou que seus familiares não queriam escutá-la chorar pela perda da filha e que na psicoterapia ela encontrou um lugar onde poderia expressar seu sofrimento: "Eu precisava dum ombro, sabe? Escutar eu chorar, escutar eu falar da minha filha, e eu não tive. Eu fui encontrar isso foi com a [psicóloga]" (Cora).

A experiência de sentir-se livre para falar e expressar seus sentimentos, relatada pelas entrevistadas, é apontada pela literatura como uma indicação de progresso no processo psicoterapêutico (Gomes et al., 1988). Elas descreveram que ao falar sobre questões pessoais que não revelavam a mais ninguém, sentiam estar "se livrando" da amargura que experimentavam, como se estivessem "desengasgando" (sic): "Saiu um peso de mim, eu guardava essas coisas com aquela amargura dentro de mim, sabe?" (Rachel). Elas também relataram que se sentiram leves ao falar sem reservas. O desvelamento de experiências pessoais importantes também foi descrito pelos participantes da pesquisa de Sousa eVaz (2017). A expressão de temas e experiências tão pessoais ocorreu quando já sentiam confiança em seus terapeutas. De modo muito semelhante ao encontrado neste estudo, essas experiências pessoais estavam vinculadas a grandes sofrimentos físicos e psicológicos que, ao ser relatados, produziam um sentimento de "desafogamento" e leveza.

Rachel chamou a atenção para o aspecto confessional da psicoterapia, pois podia falar sem sentir vergonha ou medo de que outros soubessem o que confidenciava ali. O settingterapêutico era o lugar, pois, da livre expressão. Podiam rir, chorar, expressar raiva ou desejo de vin- 
gança. Cora faz uma comparação entre as experiências que teve no grupo de ajuda mútua e na psicoterapia, destacando como positivo o fato de a escuta de sua psicóloga não possuir um viés moralizante:

Eali no grupo, ah, você tem que falar da filha, chorar e acabou-se, você não pode, assim, "ficar má", entendeu? ... Sabe, ali vocêfala só da morte e acabou-se. E não acho que é assim, eu não acho. Eu acho que você tem que falar o que você tem dentro de você, e eu, eu ... eu quero falar sobre o ódio, sobre a raiva! (Cora)

A postura não condenatória dos profissionais de saúde também esteve presente no relato de mães enlutadas entrevistadas por Gerrish et al. (2014). Segundo as entrevistadas, essa escuta permitiu que expressassem sem disfarces seu sofrimento, característica que, segundo elas, conferiu relevância à relação estabelecida com os profissionais que lhes atenderam após a perda de seus filhos.

\section{Sentir-se livre para abordar outros temas que não o luto}

As participantes relataram que, a despeito de terem procurado por psicoterapia devido ao seu luto, ao longo do processo abordaram outros temas além do luto. Rachel afirmou, inclusive, que não chegou a falar diretamente sobre a morte de sua filha e do seu luto em seu processo terapêutico. Entre os temas abordados por elas, estão questões do passado que ainda as mobilizavam, por exemplo, uma história de abandono e outra de abuso sexual.

Os relatos das entrevistadas revelam que a ocasião da perda de um filho e da consequente busca por psicoterapia é um momento em que há um esvaziamento de sentido e em que eventos anteriores à morte também encontram possibilidade de ressignificação. $\mathrm{O}$ sentimento de vazio de sentido da mãe enlutada pode se expandir para relações significativas que ela estabelece com outros membros da família (Lopes \& Pinheiro, 2013). A perda desse filho iniciaria, portanto, um processo de reflexão e de construção de sentidos (Silva \& Melo, 2013). Isso significa que mesmo questões que aparentemente não estão ligadas ao luto podem vir à tona quando da perda de alguém significativo em nossa história de vida. Os dados encontrados nos autorizam afirmar que a psicoterapia de mães enlutadas, ao enfocar na pessoa, e não somente no luto, permite a ressignificação de diversos eventos da vida dessas mães, associados de alguma maneira, mais ou menos direta, à morte de seus filhos.
A experiência de sentir-se livre para abordar outros temas além do luto esteve presente também no relato de Cecília. No seu caso, o que ela pôde abordar na terapia foram questões do seu momento de vida atual: “Discute tudo ... todas essas questões, né... 'X'aí que precisa resolver, discute com quem tá te atendendo, né?... Independente de ser só o luto, mas que tem relação com quem passou pelo luto!' (Cecília).

As mães entrevistadas relataram que ter liberdade para abordar outros temas que não o luto lhes fez bem, ainda que pudessem se sentir mal logo após. Por exemplo, quando abordavam temas do passado com os quais sentiam dificuldade para entrar em contato. Ao abordarem tais temas, tinham, no entanto, a sensação de estar "se livrando" dessas questões ou "tirando um peso" de cima delas. As entrevistadas afirmaram também que essa experiência propiciava a abertura de novas possibilidades de reflexão.

\section{Revelar o sentimento de culpa}

A culpa é um elemento frequentemente relatado na literatura sobre luto materno (Alarcão et al., 2008; Barr \& Cacciatore, 2008; Freitas \& Michel, 2014, 2015; Gerrish et al., 2014). Em um contexto social que reforça a crença de que a mãe deve ser a principal responsável pela proteção e cuidado do filho, a morte dele é percebida por ela como um fracasso em sua função materna. As participantes afirmaram que na psicoterapia tiveram a experiência de revelar seu sentimento de culpa pela perda do filho. Isso pode ser percebido em um trecho da entrevista de Cecília, no qual ela fala sobre a culpa que sente por não ter levado o filho para ser tratado em hospitais de São Paulo: "Eu já comentei com ela e tô trabalhando também, aquela questão da culpa, né? Por que que eu não exigi, eu ter ido com ele, ficado em São Paulo? Talvez teria tido outros recursos...." Alice também relatou sua experiência de revelar a culpa que sentia pela morte de seu filho, causada por uma cardiopatia congênita. A entrevistada afirmou que sentia culpa por ter transmitido o traço genético que acarretou sua morte. Ela afirmou que ao expor essa culpa à psicóloga, aos poucos deixou de senti-la, ainda que não soubesse explicar como essa mudança ocorrera.

\section{Poder se queixar dos familiares}

As entrevistadas relataram que na psicoterapia tiveram a experiência de poder se queixar de seus familiares. Alice relatou que expôs a raiva que sentia do marido e do filho por eles não quererem falar sobre seu 
filho falecido: "Uma das coisas que eu trabalhava muito com ela era a diferença do comportamento do [marido]. Porque aquilo me magoava, me feria. . . . Não achava normal. Achava que ele tava meio louco!' (Alice). Cecília também revelou ter se queixado de seus familiares. No seu caso, suas queixas estavam relacionadas às cobranças de seus filhos por mais atenção e para que deixasse de pensar na morte do irmão. Ela afirmou que, a partir dessa experiência, pôde analisar sua relação com eles, o que lhe ajudou a entender melhor seus sentimentos e a conseguir expressá-los para seus filhos.

\section{Eixo 3: Ressignificação}

O terceiro e último eixo temático contempla experiências de ressignificação vividas pelas mães durante a psicoterapia. Em seus relatos, é possível perceber que a ressignificação da relação com seus filhos que morreram abrange também a relação que possuem com os familiares e com outras pessoas significativas, a relação com a morte e também com a vida. No decorrer da psicoterapia, novos sentidos existenciais foram atribuídos aos mais diversos aspectos, lhes revelando novas possibilidades, novos modos de compreender o mundo e a si mesmas, permitindo a retomada do interesse pela vida.

\section{Perceber novas possibilidades}

Perceber novas possibilidades foi algo descrito por Cecília, ao afirmar que a psicoterapia lhe proporcionou insights e novas reflexões, ampliando sua perspectiva: "Ela [psicoterapia] vai, parece que, vamos dizer assim, abrindo, né ... o caminho, vai mostrando, né? Como seria ou como não ....". Ela relatou também que sua psicóloga não fornecia respostas prontas, mas atuava para que ela mesma as buscasse. De modo semelhante, no estudo de Gomes et al. (1988), os entrevistados relataram que dentre as mudanças que ocorreram durante a psicoterapia, havia a percepção de um novo modo de ver as coisas e de reestruturá-las. Essa percepção de novas alternativas para antigas questões também foi notada por eles quando se deparavam com o dia a dia após terem-nas abordado em terapia. A percepção de novas possibilidades de viver também foi apontada como um ganho terapêutico na pesquisa de Sousa e Vaz (2017).

\section{Alcançar a autocompreensão}

A experiência de alcançar a autocompreensão foi relatada por Cecília, que afirmou que a psicoterapia estava sendo importante para que ela pudesse entender a si e sua situação. Essa experiência esteve igualmente presente em relatos de participantes de outros estudos (Gomes et al., 1988; Sousa \& Vaz, 2017). Para alguns entrevistados do estudo de Gomes et al. (1988), o autoconhecimento foi percebido como o único benefício da psicoterapia. Nesse estudo, assim como para Cecília, os participantes afirmaram ter alcançado uma compreensão mais acurada de seus problemas, o que lhes forneceu mais subsídios para autoanálise. De modo semelhante, a mãe enlutada deste estudo relatou que passou a conseguir prestar mais atenção nela mesma, dando maior "vazão ao seu eu" e ao seu "interior": "E acho que talvez agora... eu tô conseguindo dar mais vazão ao meu eu, o meu interior... O que eu tô passando, o que eu tô vivendo ... vou pra casa pensando, vou elaborando essas questões..." (Cecília). Ela afirmou também que, durante as sessões, percebia estar conseguindo se apropriar dos temas que trabalhava com a psicóloga, como se estivesse "pegando-os pelas mãos".

\section{Aceitar a morte}

Cora afirmou que com a psicoterapia passou a entender melhor o falecimento da filha. Alice, por sua vez, relatou que sua psicoterapeuta foi fundamental para seu processo de aceitação, sem que para isso tivesse precisado oferecer alguma explicação: "É que o negócio é tão irreal, que você meio que sabe que ele morreu, mas não aceita...e esó a terapeuta que foi me fazendo ver que não... que realmente aconteceu ..." (Alice).

Ainda que as mães tenham relatado que as psicoterapeutas não lhes forneceram explicações sobre a morte de seus filhos e ainda que não saibam esclarecer o modo como se deu a ajuda que permitiu a aceitação da perda, fica evidente o quanto ao longo do processo psicoterápico a morte deixou de ser percebida como um evento irreal e incompreensível. Cabe considerar ainda que a perda de um filho provoca a quebra do tabu da imortalidade, como apontado pela literatura (Freitas \& Michel, 2015), retirando o caráter impessoal que a morte possuía na vida dessas mães. Nesse sentido, é compreensível que em um primeiro momento a morte de um filho seja um evento percebido como irreal ou absurdo, visto que essa perda rompe com a crença do senso comum de que há uma "ordem natural", segundo a qual os filhos devem morrer após os pais. Durante o processo psicoterápico esse acontecimento dramático pôde ser assimilado por elas, assumindo significações singulares. 


\section{Deixar de culpar os outros pela morte do filho}

As mudanças em psicoterapia também ocorrem em relação à experiência interpessoal (Gomes et al., 1988). No caso das participantes, foi possível notar a ressignificação de algumas relações vividas por elas. Exemplo disso é a experiência relatada por algumas entrevistadas, que deixaram de culpar outras pessoas pela morte de seus filhos. O caso de Cora ilustra essa situação. Ela culpava seu genro pela morte da filha, mas deixou de fazê-lo após trabalhar essa questão durante a terapia:

Ela pegou ele na cama com outra, aí ela ficou 15 dias internada depois piorou sabe, ele não foi ver ela. Ela faleceu, ele não foi no enterro, não foi no velório, não foi nada. E ela ficou esperando ele, sabe? Com isso, $a$ [psicóloga] já trabalhou comigo sobre isso aí sabe, eu até entendo que ele não é culpado da morte dela ... (Cora)

Outra mãe, Alice, afirmou que após o falecimento do filho sentia raiva de todas as pessoas e que a terapia lhe ajudou a entender que elas não tinham culpa pelo que ocorrera com ele: “. . . tudo isso ela foi fazendo eu ver, entender... que ninguém tinha culpa do que tinha acontecido" (Alice).

\section{Aceitar o modo dos outros de lidar com o luto}

Uma das entrevistadas relatou que passou a aceitar a maneira de seus familiares de lidar com o luto. Alice expôs que tinha dificuldade de entender a maneira pela qual o filho que permaneceu vivo e o marido, principalmente, lidavam com a perda de seu outro filho. Ela afirmou que, diferentemente dela, eles não gostavam de falar sobre o filho que falecera, fato que percebia como indiferença e que não conseguia compreender. Ao ser entrevistada, Alice destacou a importância da psicoterapia para que pudesse compreendê-los e respeitá-los e, ainda que não concordasse com a maneira deles de lidar com o luto, deixou de odiá-los por isso. Esse foi, de acordo com seu relato, o ganho mais significativo que obteve com a psicoterapia: "Se eu não tivesse ido nas sessões, conversado muito com ela, dentro da minha dor, da minha confusão, eu teria alimentado um ódio em relação a ele. Diante da minha ignorância, né? E daí eu não consegui alimentar. Pelo contrário" (Alice).

\section{Experiência de fortalecimento}

As entrevistadas relataram que a psicoterapia fez com que se sentissem fortalecidas, como expressa Alice neste breve relato: "Eu me sentia fortalecida. Toda vez que eu ia lá, eu podia entrar assim ó [expressando abatimento] ... eu saía assim [sorrindo]!”. Elas afirmaram que iam à psicoterapia "buscar forças" e que, com o processo psicoterápico, não se sentiam tão perdidas:

Que a pessoa é ... também coloca algumas perguntas, ou alguns direcionamentos, né? Que vão te dar um ... assim, parece que uma coluna de força pra você se apegar, eu acho, sabe? Pra você, tipo... não se sentir tão perdida, né? (Cecília)

É interessante notar os termos utilizados por Cecília para expressar a experiência de fortalecimento. Ela mencionou "colunas de força" em que poderia se apegar. No mesmo sentido a literatura se refere ao luto materno como um evento destruidor, capaz de estremecer por algum tempo os "pilares da vida" (Lopes \& Pinheiro, 2013; Oishi, 2014). Em um momento no qual as mães enlutadas passavam por uma experiência de instabilidade, com o estremecimento daquilo que antes lhes sustentava, a psicoterapia lhes ofereceu 0 suporte de que necessitavam. As entrevistadas também relataram que a experiência de fortalecimento vivenciada durante o processo lhes servia de auxílio para que pudessem lidar com questões familiares, como a cobrança dos demais filhos por atenção. Esses dados vão ao encontro do que foi constatado sobre a experiência de psicoterapia de viúvas no estudo de Ferreira et al. (2008), em que a participante entrevistada afirmou que com a terapia se sentiu mais fortalecida para enfrentar dificuldades.

\section{Sentir-se melhor de saúde}

Pesquisas anteriores indicam que a dor experienciada por mães que perderam seus filhos pode adquirir uma expressão física (Freitas \& Michel, 2015; Gudmundsdottir, 2009). Dentre as entrevistadas do presente estudo, duas mães apresentavam problemas de saúde que percebiam como diretamente associados ao luto. Cecília, diagnosticada com doença de Crohn, afirmou que percebeu uma melhora em relação aos sintomas da doença após realizar terapia (que estavam piores desde a perda de seu filho). Ela relatou perceber uma estreita ligação entre sua saúde men- 
tal e os problemas de intestino que a acometem: "Por causa do falecimento, né? Isso veio . . . a descarga veio pro problema de saúde, mesmo, né? Diz que isso já é esperado, é normal, né? Porque mexe, né...".

Cora foi outra mãe que afirmou ter se sentido fisicamente melhor após as sessões. Ela relatou que, nos dias em que ia à psicoterapia, não precisava do auxílio de remédios para dormir: “... Eu consigo dormir, sabe, parece que saiu aquele peso da minha cabeça. . . É a noite que eu mais durmo! Senão eu tenho que dormir à base de remédio" (Cora).

\section{Retomar a vida}

As entrevistadas relataram que a psicoterapia lhes ajudou a retomar suas vidas. Alice apontou que a psicoterapeuta lhe auxiliou na compreensão de que a vida continua após a perda de um filho. Ela acredita que a experiência de ter passado por um processo psicoterápico foi fundamental para que tivesse forças para "voltar a viver":

... O que ela mais foi incisiva foi na manutenção do meu casamento e na minha retomada da minha vida. Porque sem ela eu acho que eu teria ficado deprimida, em casa, chorando, não teria forças, não teria voltado a trabalhar, não teria ... dia após dia, né? Porque é muito lento ... voltado a viver. Ela foi fundamental nisso (Alice)

A psicoterapia é ainda descrita por elas como um "impulso" para voltar à vida e um "alicerce" para sua reconstrução. A experiência de retomar a vida envolve $o$ retorno de atividades que eram habitualmente realizadas antes da perda (cozinhar para os filhos, por exemplo) e a reconciliação com outros membros da família:

... Antes eu não conseguia fazer nada em casa, era uma coisa ... agora não. Tô conseguindo fazer alguma coisa . . . a questão de comida . . né? Pra eles ... que é uma coisa que eu gostava de fazer pra agradar um, pra agradar outro, sabe? (Cecília)

A experiência de retomar a vida também foi relatada pela viúva participante do estudo de Ferreira et al. (2008). A entrevistada afirmou que ainda se sentia triste, abatida e com vontade de morrer em alguns momentos, mesmo três anos após a morte do cônjuge. No entanto, ela afirmou que com o processo terapêutico se sentiu resgatando o interesse pela vida e a von- tade de viver. De maneira semelhante, as mães enlutadas experienciaram essa renovação do interesse pela vida. Isso se deu após um período de esvaziamento de sentido existencial, posteriormente à perda de seus filhos, quando essas mães passaram por um momento de paralisação de suas vidas - situação que é também apontada pela literatura (Silva \& Melo, 2013). A retomada da vida relatada pelas entrevistadas não implica a superação da dor do luto e do sofrimento pela perda de um filho, assim como não representa um retorno em todos os âmbitos ao modo habitual delas de existir antes da morte dos filhos. As mães relataram, porém, que puderam voltar a se engajar em atividades rotineiras e a perceber a possibilidade de um futuro, mesmo considerando a ausência de seus filhos.

\section{Considerações finais}

A vivência de psicoterapia de mães enlutadas, aqui delineada como constituída por 18 elementos inter-relacionados, pode ser descrita como a vivência de uma relação particular, estabelecida entre uma mãe enlutada e um psicoterapeuta, da qual podem emergir possibilidades de ressignificação da sua relação com seus filhos falecidos, com seus familiares, com a morte e com a própria vida. A emergência dessas possibilidades depende da qualidade dessa relação, sendo necessário que as mães se sintam acolhidas, compreendidas e adquiram confiança para poder falar sem reservas. Da liberdade que encontram nessa relação para expor seus sentimentos e abordar os temas que desejam, novos modos de perceber a própria vida se revelam e novos sentidos são atribuídos às experiências. É importante advertir, no entanto, que embora se estabeleça uma sequência de experiências que são condições para emersão de outras, não existe uma relação de causalidade entre elas.

Diferentemente daquilo que foi encontrado na pesquisa de Sousa e Vaz (2017), não esteve presente no relato das mães entrevistadas a experiência de desafios e de desestabilização da visão de mundo como parte do processo psicoterápico. Supõe-se que, no caso da psicoterapia de mães enlutadas, essa desestabilização da visão de mundo seja anterior ao processo psicoterápico, emergindo da perda do filho. Sendo assim, a vivência aqui descrita pelas mães diz respeito à experiência de uma relação na qual elas se sentiram seguras, acolhidas e compreendidas, e na qual, sob tais condições, encontraram a possibilidade de reorganizar suas visões de mundo e as relações que lhe são intrínsecas. 
Ainda que a finalidade deste estudo tenha sido alcançar uma descrição da vivência da psicoterapia de mães que perderam seus filhos, a análise das entrevistas permitiu reflexões que transcendem os limites desse objetivo inicial, suscitando novos questionamentos. Dentre os achados que podem ser assinalados, está o fato de que algumas características da relação terapeuta-paciente foram apontadas pelas mães como condições necessárias para que o processo psicoterápico pudesse ocorrer.

Outra questão que merece destaque é o fato de algumas das possibilidades que emergiram da relação terapeuta-paciente não serem comuns em outras relações vividas por essas mães. A possibilidade de serem escutadas não é algo que mães enlutadas costumam encontrar no dia a dia fora da terapia. As entrevistadas relataram o fato de amigos e familiares demonstrarem estar cansados de escutá-las. Essa situação não causa estranhamento quando se reflete sobre o contexto em que essas mães estão inseridas, no qual a morte é interdita e as expressões de luto abafadas (Ariès, 1975/2003; Koury, 2010; Kovács, 1992). Assim, importa destacar que as mães enlutadas puderam ter a experiência de expressar sofrimento na psicoterapia. Tal dado indica a relevância que um processo psicoterápico pode ter para essas mães, ao mesmo tempo que denuncia a ausência de espaços e relações em nossa sociedade em que a expressão do sofrimento seja possível.

A percepção das entrevistadas sobre a abertura das psicólogas para trabalhar com os temas que se apresentavam, sem restrições, permeou diversos elementos constituintes da vivência de psicoterapia. Essa abertura pôde ser notada no fato de as entrevistadas terem se sentido respeitadas em suas crenças, por exemplo, e quando da possibilidade de falarem sobre temas não necessária ou diretamente relacionados ao luto (tais como histórias dos tempos de infância, ou situações de abuso sexual e abandono). A possibilidade de expressar sofrimento, fraqueza e desânimo também revela a abertura encontrada por elas na psicoterapia, permitindo que se sentissem livres, sem a cobrança por uma melhora ou por uma superação da condição de enlutadas. Essa postura propiciou o desvelar de novos sentidos e possibilidades, percebido por elas como algo positivo. Esses dados nos levam a questionar se um projeto psicoterápico que seja livre de limites quanto aos temas que devem ser abordados e em relação a objetivos prévios poderia ser mais benéfico para pessoas enlutadas. Mais estudos seriam necessários para que se pudesse sair em defesa dessa tese no contexto da psicoterapia de mães enlutadas e de enlutados em geral.

O respeito à autonomia do paciente é outro ponto que merece ser destacado. Nos relatos das participantes, a autonomia surge como uma condição para a ressignificação, como demonstrou Cecília ao comparar o fazer do psicoterapeuta com pais que auxiliam o filho no dever de casa sem lhe dar, no entanto, respostas prontas para a resolução das questões. Se considerarmos que o sentido de uma vivência sempre é dado por aquele que a vivenciou, seremos obrigados a concordar que só quem pode atribuir um sentido novo a esta, ou seja, ressignificá-la, é a pessoa que a vivenciou. Sendo assim, apontamos para a relevância da preservação da autonomia de mães enlutadas em suas psicoterapias, pois permite o desvelamento de novas possibilidades de sentido.

Por fim, a experiência de retomar a vida indica que uma mudança significativa foi vivenciada por essas mães no decorrer de seus processos psicoterápicos. Cabe ressaltar, no entanto, que essa experiência não representa o término do luto ou sua superação. A experiência de retomar a vida é descrita como um retorno às atividades rotineiras e a percepção da possibilidade de um futuro, considerando a ausência do filho. Não é, portanto, o desfecho de um processo em que a dor e o sofrimento da perda do filho cessam completamente, mas sim a experiência de redescoberta da existência de sentido na vida. Esse elemento constituinte da vivência de mães enlutadas na psicoterapia provoca a reflexão sobre quais seriam os objetivos de um processo psicoterapêutico para mães que perderam seus filhos: a resolução do luto, concebido como algo que deve ser "tratado, abreviado e apagado" (Ariès, 1975/2003, p. 95), ou a abertura de possibilidades de novos sentidos diante dessa nova condição em que essa mãe é lançada? Essa é outra questão que poderia ser retomada em estudos posteriores.

Ainda que os resultados deste estudo não sejam universais, eles são, sim, generalizáveis, pois, aplicando-se a análise eidética (variação livre imaginativa), tornou-se possível eliminar particularidades e contingências do fenômeno em questão e chegar à estrutura psicológica geral da experiência vivida. Por óbvio, a compreensão do sentido de uma determinada vivência deve considerar o contexto em que ela se articula. Sendo assim, ao realizar a generalização dos achados desta pesquisa, não se deve desprezar o fato 
de que as participantes são todas mães enlutadas que fazem parte de um mesmo grupo de ajuda mútua para enlutados de uma cidade do sul do país.

Em uma reflexão sobre os possíveis modos de cuidado que podem ser oferecidos aos enlutados, a experiência vivida dos próprios enlutados não pode ser desprezada. Afinal, é para eles que se destinam esses serviços. Nesse sentido, este estudo oferece sua contribuição ao dar visibilidade a uma vivência singular que tem o potencial de sensibilizar e preparar psicoterapeutas para lidarem com pessoas que vivenciam o luto, além de abrir caminho para novas pesquisas que visem o aprimoramento da prática psicoterápica com mães que perderam seus filhos.

\section{Referências}

Alarcão, A. C. J., Carvalho, M. D. B., \& Pelloso, S. M. (2008). A morte de um filho jovem em circunstância violenta: Compreendendo a vivência da mãe. Revista Latino-Americana de Enfermagem, 16(3), 341-347. https:// doi.org/10.1590/S0104-11692008000300002

Ariès, P. (2003). História da morte no ocidente. Ediouro. (Trabalho original publicado em 1975)

Barr, P., \& Cacciatore, J. (2008). Problematic emotions and maternal grief. Omega, 56(4), 331-348. https://doi.org/10.2190/ OM.56.4.b

Brice, C. W. (1991). What forever means an empirical existential-phenomenological investigation of maternal mourning. Journal of Phenomenological Psychology, 22(1), 16-38. https://doi.org/10.1163/156916291X00028

Ekroll, V. B., \& Rønnestad, M. H. (2017). Processes and changes experienced by clients during and after naturalistic good-outcome therapies conducted by experienced psychotherapists. Psychotherapy Research, 27(4), 450-468. https://doi.org/10.1080/10503307.2015.1119326

Ferreira, L. V., Leão, N. C., \& Andrade, C. C. (2008). Viuvez e luto sob a luz da Gestalt-terapia: Experiências de perdas e ganhos. Revista da Abordagem Gestáltica, 14(2), 153-160.

Forghieri, Y. C. (2012). Psicologia fenomenológica: Fundamentos, métodos e pesquisas. Cengage Learning. (Trabalho original publicado em 1993)

Franco, M. H. P. (2010). Formação e rompimento de vínculos: O dilema das perdas na atualidade. Summus.

Freitas, J. L. (2018). Bereavement, pathos, and clinical psychology: A phenomenological reading. Psicologia USP, 29(1), 50-57. https://doi.org/10.1590/0103-656420160151

Freitas, J. L., \& Michel, L. H. F. (2014). A maior dor do mundo: O luto materno em uma perspectiva fenomenológica. Psicologia em Estudo, 19(2), 273-283. https://doi.org/10.1590/1413-737222324010

Freitas, J. L., \& Michel, L. H. F. (2015). A vivência do luto materno: Um olhar fenomenológico-existencial. In J. L. Freitas, \& M.V. F. Cremasco (Orgs.), Mães em luto: A dor e suas repercussões existenciais e psicanalíticas (pp. 25-44). Juruá.

Gelso, C. (2014). A tripartite model of the therapeutic relationship: Theory, research, and practice. Psychotherapy Research, 24(2), 117-131. https://doi.org/10.1080/10503307.2013.845920

Gerrish, N. J., Neimeyer, R. A., \& Bailey, S. (2014). Exploring maternal grief: A mixed-methods investigation of mothers' responses to the death of a child from cancer. Journal of Constructivist Psychology, 27(3), 151-173. https:// doi.org/10.1080/10720537.2014.904700

Giorgi, A., \& Sousa, D. (2010). Método fenomenológico de investigação em psicologia. Fim de Século.

Gomes, W. B. (1990). A experiência retrospectiva de estar em psicoterapia: Um seguimento. Psicologia: Teoria e Pesquisa, 6(1), 87-105.

Gomes, W. B., Reck, A., \& Ganzo, C. (1988). A experiência retrospectiva de estar em psicoterapia: Um estudo empírico fenomenológico. Psicologia: Teoria e Pesquisa, 4(3), 187-206.

Gudmundsdottir, M. (2009). Embodied grief: Bereaved parents' narratives of their suffering body. Omega: Journal of Death and Dying, 59(3), 253-269. https:// doi.org/10.2190/OM.59.3.e

Koury, M. G. P. (2010). Ser discreto: Um estudo sobre o processo de luto no Brasil urbano no final do século XX. Revista Brasileira de Sociologia da Emoção, 9(25).

Kovács, M. J. (1992). Morte e desenvolvimento humano. Casa do Psicólogo. 
Lambert, M. J. (2013). Outcome in psychotherapy: The past and important advances. Psychotherapy, 50(1), 42-51. https://doi.org/10.1037/a0030682

Lopes, C. M. B., \& Pinheiro, N. N. B. (2013). Notas sobre algumas implicações psíquicas da desconstrução da maternidade no processo de luto: Um caso de nascimento-morte. Estilos da Clínica, 18(2), 358-371.

Martins, G. (2001). Laços atados: A morte do jovem no discurso materno. Moinho do Verbo.

Oishi, K. L. (2014). O jardim de Julia: A vivência de uma mãe durante o luto. Psicologia: Teoria e Pesquisa, 30(1), 5-11.

Parkes, C. M. (1998). Luto: Estudos sobre a perda na vida adulta. Summus.

Pieta, M. A., Castro, T. G., \& Gomes, W. B. (2012). Psicoterapia e pesquisa: Desafios para os próximos 10 anos no Brasil. In A. F. Holanda (Org.), O campo das psicoterapias: Reflexões atuais (pp. 121-142). Juruá.

Silva, P. K. S. (2013). Experiências maternas de perda de um filho com câncer infantil: Uma compreensão fenomenológico-existencial [Dissertação de Mestrado]. Universidade Federal do Rio Grande do Norte.

Silva, P. K. S., \& Melo, S. F. (2013). Experiência materna de perda de um filho com câncer infantil: Um estudo fenomenológico. Revista da Abordagem Gestáltica, 19(2), 147-156.

Sousa, D., \& Vaz, A. (2017). Significant events identified by clients engaged in existential psychotherapy: A descriptive phenomenological exploration. Journal of Humanistic Psychology, 60(6), 829-848. https:// doi.org/10.1177/0022167817716304

Stiles, W. B. (2012). The variables problem and progress in psychotherapy research. Psychotherapy, 50(1), 33-41. https://doi.org/10.1037/a0030569

Timulak, L. (2007). Identifying core categories of client-identified impact of helpful events in psychotherapy: A qualitative meta-analysis. Psychotherapy Research, 17(3), 305-314. https://doi.org/10.1080/10503300600608116

Timulak, L. (2010). Significant events in psychotherapy: An update of research findings. Psychology and Psychotherapy: Theory, Research and Practice, 83(4), 421-447. https://doi.org/10.1348/147608310X499404

Luís Henrique Fuck Michel

Mestre em Psicologia pela Universidade Federal do Paraná (UFPR), Curitiba - PR. Brasil.

E-mail: luis.hfmichel@gmail.com

(1) https://orcid.org/0000-0002-5063-9502

Joanneliese de Lucas Freitas

Doutora em Psicologia pela UFPR, Curitiba - PR. Brasil.

E-mail: joanneliese@gmail.com

(1) https://orcid.org/0000-0002-0856-3460

Agradecimento à Coordenação de Aperfeiçoamento de Pessoal de Nível Superior (Capes) pelo financiamento da pesquisa.

Endereço para envio de correspondência:

Praça Santos Andrade, 50, sala 215, Ala Alfredo Bufren, Centro. CEP: 80060-240. Curitiba - PR. Brasil.

Recebido 21/12/2017

Aceito 12/08/2019

Received 12/21/2017

Approved 08/12/2019

Recibido 21/12/2017

Aceptado 12/08/2019 
Como citar: Michel, L. H. F., Freitas, J. L. (2021). Psicoterapia e luto: A vivência de mães enlutadas. Psicologia: Ciência e Profissão, 41 (n.spe 3), 1-15. https://doi.org/10.1590/1982-3703003189422

How to cite: Michel, L. H. F, Freitas, J. L. (2021). Psychotherapy and bereavement: The experience of mourning mothers. Psicologia: Ciência e Profissão, 41 (n.spe 3), 1-15. https://doi.org/10.1590/1982-3703003189422

Cómo citar: Michel, L. H. F., Freitas, J. L. (2021). Psicoterapia y duelo: La vivencia de madres enlutadas. Psicologia: Ciência e Profissão, 41 (n.spe 3), 1-15. https://doi.org/10.1590/1982-3703003189422 